\title{
Fat quality of South African pigs with different carcass classification characteristics
}

\author{
A. Hugo" \& E. Roodt \\ Food Science Division, Department of Microbial, Biochemical and Food Biotechnology, \\ University of the Free State, PO Box 339, Bloemfontein, 9300, South Africa
}

(Received 15 August 2014; Accepted 16 April 2015; First published online 5 August 2015)

\begin{abstract}
Copyright resides with the authors in terms of the Creative Commons Attribution 2.5 South African Licence.
See: http://creativecommons.org/licenses/by/2.5/za

Condition of use: The user may copy, distribute, transmit and adapt the work, but must recognise the authors and the South African Journal of Animal Science.
\end{abstract}

\begin{abstract}
The carcasses of South African pigs are classified into six groups (PORCUS) according to their calculated lean meat content and measured backfat thickness. Pigs with the highest lean meat content and lowest backfat thickness belong to the $\mathrm{P}$ group. Fat quality of backfat from 2107 pig carcasses, sampled within the different pork classification groups at a major South African pig abattoir, was evaluated to determine the relationship between carcass classification and backfat quality. Extracted fat was used to determine the iodine value of these samples. Significant differences in carcass characteristics and iodine value were observed between the classification groups. Improved fat quality, indicated by a lower iodine value, was associated with increased backfat thickness and decreased lean meat content. The $P$ and $O$ classification groups (with backfat thickness $<17 \mathrm{~mm}$ ) could not conform to international standards proposed for good technological quality backfat. The $\mathrm{C}, \mathrm{U}$ and $\mathrm{S}$ groups (with backfat between 23 and $>32 \mathrm{~mm}$ ) possessed good technological quality backfat. Backfat from the $\mathrm{R}$ group had borderline fat quality. Correlation analyses were employed to acquire equations to describe relationships between iodine value and carcass classification data. The French classification system predicts fat quality by utilizing backfat thickness and lean meat content. It was proposed, through modification of the French system, that South African pig carcasses with a backfat thickness $>17 \mathrm{~mm}$ and a lean meat content $<67 \%$ would potentialy deliver good quality backfat. Results from this study indicate that carcass classification data may be used to improve the probability of selecting pig carcasses with good quality fat.
\end{abstract}

\footnotetext{
Keywords: Backfat, fatty acid(s), iodine value, meat processing, South Africa, survey, swine

\#Corresponding author: HugoA@ufs.ac.za
}

\section{Introduction}

Feed ingredients rich in polyunsaturated fatty acids (PUFA) have the potential to produce soft backfat (BF) with poor technological properties and decreased storage stability, which is of concern to the meat processing industry (Madsen et al., 1992; Verbeke et al., 1999). Lipid quality plays an important role in the production of meat products (Miklos et al., 2011). Meat products containing these adipose tissues, often called soft fat, show defects such as insufficient drying, oily appearance, rancidity development and lack of cohesiveness between muscle and adipose tissue on cutting (Bailey et al., 1973; Gandemer, 2002; Hugo \& Roodt, 2007). The more expensive processed meat products such as bacon and fermented sausages (salami) are especially affected by poor fat quality (Fischer, 1989a; b; Prabucki, 1991; Häuser \& Prabucki, 1990; Bothma et al., 2014). As a rule, fats with higher unsaturated fatty acid contents have a softer consistency, lower melting point and greater susceptibility to oxidative spoilage (Fischer, 1989a). Other factors such as genotype, sex, condition, slaughter mass, high fat diets and restricted feeding levels could produce unacceptably soft fat tissue (Bruwer, 1992).

The global decrease in overall fatness of pigs has caused the fatty acid (FA) profile of pigs to change to a more unsaturated one, which is beneficial to the consumer, but that leads to many problems during the manufacture of processed meat products. Too much unsaturated fatty acids lead to an inferior consistency, economical losses, and processing, quality, storage and taste disadvantages (Affentranger et al., 1996). The unsaturation of pork BF is further increased by the addition of large amounts of PUFA in feed. A high PUFA content causes BF to be soft and difficult to cut and handle during processing (Madsen et al., 1992; Verbeke et al., 1999). Fish meal, maize, soybean oilcake, sunflower oilcake and wheaten bran are feed ingredients rich in PUFA and commonly used in pig diets in South Africa (Viljoen \& Ras, 1991). 
Conventional methods for fat quality measurement, such as FA profiles, iodine value (IV), melting point and slip point determination, require expensive equipment, are expensive to perform or are time consuming (Andersen et al., 1999). In Switzerland fat score is used as an indicator of fat quality. Fat score refers to the iodine number and is related to the degree of unsaturation of the outer layer of the BF (Hadorn et al., 2008). Iodine value is a commonly used method to determine fat quality and several IVs were proposed as the cut-off point for good fat quality. To avoid problems arising from the use of unsuitable raw materials in the manufacture of firm-cutting sausage, the utilized BF should have an IV of no more than 60 (Fischer, 1989b). According to Lea et al. (1970), hard adipose tissues have an IV lower than 65 and soft adipose tissues an IV higher than 70. Mortensen et al. (1983) proposed an IV of below 65 in BF as critical from a quality point of view, while Barton-Gade (1987) indicated that a maximum IV of 70 would produce firm fat. Other authors have agreed that the cut-off point for good quality BF should be 70 (Houben \& Krol, 1983; Girard et al., 1988).

In France, the need for a simple method of selecting adipose tissues led to the development of an indirect method based on classification data like lean meat content (LMC) $(<57 \%)$ and backfat thickness (BFT) (>15 mm) (Davenel et al., 1999). This method is based on observations that adipose tissues with the lowest thickness lack consistency because they have the highest proportion of PUFA and the lowest proportion of satured fatty acids (Lea et al., 1970; Villegas et al., 1973; Wood, 1973). Carcass LMC is calculated from two BFT measurements and one muscle thickness measurement. Although this method limits the risk of selecting pig carcasses with soft fat (Rampon et al., 1994), it does not guarantee quality because soft adipose tissues may still escape detection.

The system used by the French for predicting fat quality might be applicable to South African conditions. Certain modifications would, however, have to be made because a different formula is used to calculate LMC in France and measurements are taken at different places on the carcass. In South Africa, according to Bruwer (1991), no distinction is made between sex, whereas in France sex differentiation exists. Bruwer (1991) further stated that the current classification system was implemented in South Africa in 1991. It entails the calculation of LMC by means of a single measurement of BF and muscle thickness taken by either the Hennesey Grading Probe (HGP - a light reflectance probe) or the Intrascope (an optical probe). In South Africa the following parts are not taken into account: flare fat, kidneys, kidney fat and glands, fore and hind trotters as well as the head and tail, in both the formulas used to caluculate \%LMC (Bruwer, 1991). Differences in carcass yield among carcasses in the European Union (EU), Canada and the United States are influenced by the definition used (Marcoux et al., 2007). In the EU and Canada, generally, the head, tail and trotters together with the four primal cuts, are included in the calculation of lean yield.

In the case of the HGP, BF and muscle thickness measurements are used to calculate \%LMC, while the Intrascope uses only BFT measurements. This measurement is made between the 2nd and 3rd last rib, $45 \mathrm{~mm}$ from the carcass midline (Bruwer et al., 1991). When the HGP is used,

$\% \mathrm{LMC}=72.5114-0.4618 \mathrm{~V}+0.0547 \mathrm{~S}$

where $V=$ BFT in $\mathrm{mm}$ and $S=$ muscle thickness in $\mathrm{mm}$ (Bruwer et al., 1991). Pigs are then classified into one of six groups, PORCUS, according to their \%LMC: $\mathbf{P}=\geq 70 \%$ LMC; $\mathbf{O}=68 \%-69 \%$ LMC; $\mathbf{R}=66 \%-$ $67 \%$ LMC; $\mathbf{C}=64 \%-65 \%$ LMC; $\mathbf{U}=62 \%-63 \%$ LMC; $\mathbf{S}=\leq 61 \%$ LMC (SAMIC, 2014). In cases where the Intrascope is used, the formula changes to: \% LMC $=74.4367-0.4023 \mathrm{~V}$ where $V=$ BFT in $\mathrm{mm}$. The PORCUS system classifies pigs in the following BFT groups (as measured by the Intrascope): $\mathbf{P}=\leq 12 \mathrm{~mm}$; $\mathbf{O}=13-17 \mathrm{~mm} ; \mathbf{R}=18-22 \mathrm{~mm} ; \mathbf{C}=23-27 \mathrm{~mm} ; \mathbf{U}=28-32 \mathrm{~mm}$ and $\mathbf{S}=>32 \mathrm{~mm}$ (SAMIC, 2014). The values proposed by the French for good quality ( $\mathrm{LMC}<57 \%$ and BFT $>15 \mathrm{~mm}$ ) will therefore have to be recalculated for the South African classification system.

The objectives of this study were to determine whether fat quality of pig carcasses differed between the respective classification groups (PORCUS) in the SA pig classification system, to ascertain the probability of selecting pig carcasses with good fat quality from the different classification groups and to determine whether BFT and LMC may be used to predict fat quality of these carcasses.

\section{Materials and Methods}

Sampling was done over a period of one year at the Pork Packers abattoir in Olifantsfontein, South Africa. At monthly intervals a total of 2107 pig carcasses were sampled. This total consisted of $45 \mathrm{BF}$ samples collected from each of the $\mathrm{P}, \mathrm{O}$ and $\mathrm{R}$ classification (thinner BFT) groups and as many as available of the $\mathrm{C}, \mathrm{U}$ and $\mathrm{S}$ (thicker BFT) groups during each monthly sampling. Every third pig carcass in the slaughtering line, on its way from cold storage to the deboning area, was identified (marked and numbered) for sampling and the relevant information on the carcass was recorded. This information included classification data, classification group, cold carcass mass and identification number of the producer. Backfat samples were collected \pm 24 hours after slaughter in the deboning section of the abattoir. After being divided into the six primal cuts, the identified carcasses were sampled next to the stationary bandsaw. Approximately 
$2 \mathrm{~g}$ of fat (consisting of both inner and outer layer sampled together as one sample, regardless of either layer's thickness) was removed $45 \mathrm{~mm}$ from the midline position between the $2 \mathrm{nd}$ and $3 \mathrm{rd}$ last rib at the same position as the hole made by the HGP.

Each sample was then packed into an impermeable, numbered plastic pouch and stored on ice in the abattoir as well as during transportation to the laboratory in Bloemfontein. These samples were cut into small pieces and well mixed to form a representative sample. The reason for using a mixed sample (consisting of inner as well as outer layer) is that South African meat processors do not separate the inner and outer layers, but use both layers together in the manufacturing of meat products. These samples were then transferred into marked Nunc ${ }^{\mathrm{TM}}$ cryotubes and stored in liquid nitrogen until analyzed. All the relevant grading information (warm carcass mass, cold carcass mass, BFT, muscle thickness and LMC of each pig) was obtained from the abattoir's computer system.

Total lipid from approximately $1 \mathrm{~g}$ of BF was quantitatively extracted according to the method of Folch et al. (1957), using chloroform and methanol in a ratio of $2: 1$. An antioxidant, butylated hydroxytoluene, was added to the chloroform : methanol mixture at a concentration of $0.001 \%$. A rotary evaporator was used to dry the fat extracts under vacuum and the extracts were also dried overnight in a vacuum oven at $50^{\circ} \mathrm{C}$, using phosphorus pentoxide as moisture adsorbent. Total extractable fat content (EFC) was determined by weighing and expressed as \%fat (w/w) per $100 \mathrm{~g}$ tissue. The extracted fat was stored in a polytop (glass vial, with push-in top) under a blanket of nitrogen and frozen at $-20^{\circ} \mathrm{C}$ until further analyzed. A sample of $0.5 \mathrm{~g}$ lipid, extracted by the above method, was used to determine the Hanus IV (AOAC, 2000). Iodine value was calculated as follows:

$$
\text { Iodine value }=\frac{\text { (titration number of blank }- \text { titration number of sample) } \times \text { normality of sodiumthiosulphate } \times 126.91}{\text { weight of sample } \times 10}
$$

and expressed as number of gram iodine absorbed by $100 \mathrm{~g}$ of fat, which indicates the unsaturation of the fat. Reagents used were all of analytical grade and were obtained from Merck, Halfway House, South Africa, unless stated otherwise.

A one-way analysis of variance (ANOVA) procedure and the Tukey-Kramer multiple comparison test $(\alpha=0.05)$ (NCSS, 2007) were carried out to determine whether significant differences between different classification groups existed. Pearson correlation analyses were performed to determine the relationship between IV and classification parameters (warm and cold carcass mass, BFT at $45 \mathrm{~mm}$, muscle thickness and LMC) and to ascertain the factors that best predict fat quality (NCSS, 2007). Individual scatterplots of IV against classification parameters (BFT and LMC) were constructed. Linear, power, logarithmic and exponential trendlines were alternately fitted to each graph to determine the best fit (with respect to the $r$ value) between carcass classification parameters and IV. This was done in an attempt to determine alternative cut-off points for fat quality criteria at selected IVs (60 and 70), which could be used to modify the French system of predicting fat quality applicable to South African conditions. The corresponding classification values (BFT and LMC) were calculated from these scatterplots by substitution of the $x$-value with the value of the cut-off point and calculating the corresponding $y$-value from the equation that produced the best fit (with respect to the $r$ value). The percentage of pigs conforming to different international fat quality requirements within each classification group was also calculated by expressing the number of pigs complying with international criteria as a percentage of the total number of pigs in each group. These percentages were tabulated in order to determine the probability of selecting pigs with good fat quality from specific BFT groups.

\section{Results and Discussion}

The average warm carcass weight of all the pigs was $75.6 \pm 6.25 \mathrm{~kg}$, as indicated in Table 1 . That made the pig carcasses used in this trial representative of pigs currently slaughtered in South Africa. According to Streicher (2014, S. Streicher, South African Pork Producers Organization, PO Box 36207, Menlo Park, 0102), the average carcass mass in South Africa is $75 \mathrm{~kg}$. Differences $(P<0.001)$ were observed between classification groups for all carcass grading characteristics (warm and cold carcass weight, BFT, LMC and muscle thickness) (Table 1). The BFT (45 mm) differed significantly between the PORCUS classification groups. The O, R, C, U and S groups had BFT of more than $15 \mathrm{~mm}$, which was the minimum that Davenel et al. (1999) proposed for good quality BF, as depicted in Table 2. The R, C, U and S groups had BFT values of more than $17.5 \mathrm{~mm}$ (Cannon et al., 1996) and $18 \mathrm{~mm}$ (Prabucki, 1991), thus having the potential to produce good quality BF, according to international standards.

According to Cannon et al. (1996), BF with optimum quality should be between $17.5 \mathrm{~mm}$ and $20 \mathrm{~mm}$ thick. Should this guideline be applied in South Africa, only the R group would have the potential to produce 
Table 1 Carcass characteristics of pigs (Mean \pm SD) within the different classification groups of the South African pig classification system

\begin{tabular}{|c|c|c|c|c|c|c|c|}
\hline & \multicolumn{6}{|c|}{ Carcass classification } & \multirow{2}{*}{ All pigs } \\
\hline & $\mathbf{P}$ & 0 & $\mathbf{R}$ & C & $\mathbf{U}$ & $\mathbf{S}$ & \\
\hline Number of pigs & 539 & 539 & 544 & 347 & 102 & 36 & 2107 \\
\hline Warm carcass weight $(\mathbf{k g})$ & $71.82^{a} \pm 5.74$ & $75.25^{c} \pm 5.70$ & $76.72^{\mathrm{D}} \pm 5.78$ & $78.44^{\mathrm{a}} \pm 5.52$ & $80.10^{\mathrm{a}} \pm 5.59$ & $79.36^{\mathrm{ab}} \pm 6.10$ & $75.58 \pm 6.25$ \\
\hline Min. & 53.40 & 57.60 & 59.00 & 61.00 & 65.60 & 66.60 & 53.40 \\
\hline Max. & 87.00 & 96.70 & 97.50 & 91.40 & 97.30 & 91.40 & 97.50 \\
\hline Cold carcass weight (kg) & $69.83^{d} \pm 5.73$ & $73.25^{c} \pm 5.70$ & $74.72^{b} \pm 5.78$ & $76.44^{a} \pm 5.52$ & $78.10^{\mathrm{a}} \pm 5.59$ & $77.36^{\mathrm{ab}} \pm 6.10$ & $73.58 \pm 6.24$ \\
\hline Min. & 51.40 & 55.60 & 57.00 & 59.00 & 63.60 & 64.60 & 51.40 \\
\hline Max. & 85.00 & 94.70 & 95.50 & 89.40 & 95.30 & 89.40 & 95.50 \\
\hline BFT (45 mm) & $11.61^{\dagger} \pm 1.15$ & $15.05^{\mathrm{e}} \pm 1.26$ & $18.77^{d} \pm 1.32$ & $22.97^{C} \pm 1.35$ & $26.95^{b} \pm 1.39$ & $31.41^{\mathrm{a}} \pm 2.55$ & $17.29 \pm 5.00$ \\
\hline Min. & 7.20 & 12.00 & 15.20 & 18.40 & 23.20 & 28.00 & 7.20 \\
\hline Max. & 14.40 & 18.00 & 22.40 & 26.40 & 29.60 & 40.00 & 40.00 \\
\hline MT (mm) & $53.86^{\mathrm{a}} \pm 5.32$ & $52.55^{\mathrm{b}} \pm 5.13$ & $51.20^{C} \pm 5.23$ & $50.19^{C} \pm 5.74$ & $48.22^{a} \pm 5.72$ & $44.54^{\mathrm{e}} \pm 7.70$ & $51.80 \pm 5.68$ \\
\hline Min. & 38.40 & 35.60 & 23.60 & 24.40 & 26.40 & 24.00 & 23.60 \\
\hline Max. & 69.20 & 67.60 & 64.40 & 64.80 & 59.20 & 59.20 & 69.20 \\
\hline LMC (\%) & $70.10^{\mathrm{a}} \pm 0.50$ & $68.43^{\mathrm{b}} \pm 0.56$ & $66.64^{c} \pm 0.56$ & $64.65^{d} \pm 0.57$ & $62.70^{\mathrm{e}} \pm 0.57$ & $60.44^{\dagger} \pm 1.15$ & $67.36 \pm 2.40$ \\
\hline Min. & 69.30 & 67.50 & 65.50 & 63.50 & 61.50 & 56.60 & 56.60 \\
\hline Max. & 72.00 & 69.40 & 67.40 & 65.40 & 63.50 & 61.40 & 72.00 \\
\hline
\end{tabular}

Means with different superscripts within the same row differ significantly $(P<0.001)$.

SD: standard deviation; BFT: backfat thickness; MT: muscle thickness; LMC: lean meat content.

Min. = Minimum value observed; Max. = Maximum value observed

Table 2 Chemical properties of subcutaneous fat of pigs within the different classification groups of the South African pig classification system

\begin{tabular}{|c|c|c|c|c|c|c|c|}
\hline & \multicolumn{6}{|c|}{ Carcass classification } & \multirow{2}{*}{ All pigs } \\
\hline & $\mathbf{P}$ & 0 & $\mathbf{R}$ & C & $\mathbf{U}$ & $\mathbf{S}$ & \\
\hline Number of pigs & 539 & 539 & 544 & 347 & 102 & 36 & 2107 \\
\hline Extractable fat (\%) & $70.22^{e} \pm 5.07$ & $74.43^{d} \pm 3.89$ & $77.00^{c} \pm 3.01$ & $78.69^{b} \pm 2.80$ & $79.94^{a} \pm 2.16$ & $79.95^{\mathrm{ab}} \pm 3.28$ & $75.08 \pm 5.03$ \\
\hline Min. & 26.23 & 58.79 & 63.32 & 62.50 & 69.16 & 67.72 & 26.23 \\
\hline Max. & 80.85 & 82.85 & 83.90 & 84.34 & 83.82 & 84.15 & 84.34 \\
\hline lodine value & $76.95^{\mathrm{a}} \pm 5.15$ & $73.01^{\mathrm{D}} \pm 4.61$ & $70.65^{C} \pm 4.20$ & $68.97^{a} \pm 4.00$ & $68.21^{a} \pm 3.86$ & $67.46^{a} \pm 3.67$ & $72.42 \pm 5.45$ \\
\hline Min. & 62.75 & 62.05 & 60.26 & 59.26 & 58.15 & 62.12 & 58.15 \\
\hline Max. & 96.13 & 98.46 & 86.73 & 81.56 & 82.09 & 78.81 & 98.46 \\
\hline
\end{tabular}

Means with different superscripts within the same row differ significantly $(P<0.001)$.

Min. = minimum value observed; Max. = maximum value observed 
optimum fat quality (Table 1). From this table it is evident that with increased BFT, LMC significantly decreased; it can therefore be said that they were inversely correlated. Significant differences were also observed in \%LMC between the different classification groups (Table 1). The P classification group had an average LMC of $70.1 \%$, while the corresponding value in the $S$ classification group was $60.4 \%$. No classification group could conform to the maximum LMC of $57 \%$ proposed by Davenel et al. (1999) for good fat quality. The necessity of recalculating this value to be able to conform to South African conditions is therefore evident, as by far the majority of pigs did not conform to a maximum LMC of $57 \%$. This discrepancy may be attributed to the fact that yield definitions differ between different countries (Marcoux et al., 2007). In South Africa, flare fat, kidneys, kidney fat and glands, fore and hind trotters as well as the head and tail are not taken into account in both the formulas used to caluculate \%LMC (Bruwer, 1991). In the EU and Canada the head, tail and trotters, together with the four primal cuts are generally included in the calculation of the lean yield (Marcoux et al., 2007).

In Table 2, EFC showed an increase $(P<0.001)$ with decreased LMC and increased BFT (i.e. from the $P$ to the $S$ classification group). None of the groups could reach the minimum value of $84 \%$ proposed by Prabucki (1991) for good quality fat. Although the $U$ and S groups had average values of $79.9 \%$ and $80.0 \%$, respectively, Table 2 indicates that individual pigs in the $\mathrm{O}$ and $\mathrm{S}$ groups could surpass the $84 \%$ limit (84.3\% was observed in the $\mathrm{O}$ group and $84.2 \%$ in the $\mathrm{S}$ group). The average \%EFC for all pigs was $75.1 \%$, approximately $9 \%$ lower than the proposed value of $84 \%$. The $\% E F C$ in pork fat is of economic importance for the production of lard (Barton-Gade, 1983).

The IV decreased significantly $(P<0.001)$ with increased BFT and decreased LMC (Table 2). Fischer (1989b) indicated that the IV of BF used in the manufacturing of firm-cutting sausage had to be less than 60 to avoid any problems. This requirement could not be met by any of the classification groups (if mean values of each group are taken into account). Individual pigs in the $\mathrm{C}$ and $\mathrm{U}$ groups could comply with this requirement, highlighting the effect of breed, environmental and feeding differences. This is probably the consequence of South African diets being based on maize while European diets are barley based. It is known that maize causes softer fat (Viljoen \& Ras, 1991). Technically, if this requirement is used as a limit, no firm-cutting sausages could be manufactured in South Africa. Lea et al. (1970) proposed that an IV of lower than 65 would result in hard adipose tissue, while an IV higher than 70 would lead to soft adipose tissue. Mortensen et al. (1983) also proposed that an IV of below 65 in BF would result in good quality BF. Hart (1956) indicated that BF would be soft at an IV of 66 or above, while Ten Cate (1968) indicated that fats with an IV of 66 will cause problems in firm-cutting sausages. Lo Fiego et al. (2005) proposed an IV <70 for good ham production.

No mean value of any PORCUS-group could comply with the maximum limits of 65 and 66, but individual pigs in all groups had IVs below 65 and 66 (Table 2). If an IV of less than 70 (Houben \& Krol, 1983; Barton-Gade, 1983; 1987; Girard et al., 1988) is taken as a measure of good quality BF, the C, U and S groups realized mean IV lower than 70 . The average IV of 72.4 for all pigs was above the maximum IV of 60, 65, 66 and 70, proposed, respectively, which would indicate that the average South Afircan pig has soft $\mathrm{BF}$, according to international standards. The IV is very important in Switzerland, because it is incorporated into their payment system (Affentranger et al., 1996). Should producers deliver pigs with unacceptably high IV, it would lead to a decrease in their gross profit margin. Previous work has shown that a thinner BF layer corresponds to a lower \%EFC and a higher IV (Barton-Gade, 1983).

Table 3 indicates Pearson correlation coefficients between the carcass characteristics (BFT, measured at $45 \mathrm{~mm}$, muscle thickness, LMC and carcass weights) and IV. Highly significant correlations

Table 3 Pearson correlation coefficients ( $r$ ) and significance levels of correlations between iodine value (IV) and carcass characteristics

\begin{tabular}{lrc}
\hline Parameter & IV & $P$ \\
\hline Warm carcass weight $(\mathrm{kg})$ & -0.3747 & $\star \star \star$ \\
Cold carcass weight $(\mathrm{kg})$ & -0.3747 & $\star \star \star$ \\
BFT (45 mm) & -0.5610 & $\star \star \star$ \\
MT (mm) & 0.0921 & $\star \star \star$ \\
LMC (\%) & 0.5531 & $\star \star \star$
\end{tabular}

$\star \star \star \overline{P<0.001 . ~ I V: ~ i o d i n e ~ v a l u e . ~ B F T ~(45 ~ m m): ~ b a c k f a t ~ t h i c k n e s s ~} 45 \mathrm{~mm}$ from midline; MT: muscle thickness, LMC: lean meat content; $n=2107$. 
were observed between all parameters except muscle thickness, which was poorly correlated with IV $(r=0.0921)$. Backfat thickness $(45 \mathrm{~mm})(r=-0.5610)$ and LMC $(r=0.5531)$ correlated best and second best with IV, respectively. Martin et al. (1972) indicated that IV was negatively and positively correlated with measures of fat and lean, respectively.

From the above discussion it is evident that closer investigation into the international limits set for the carcass characteristics (BFT and LMC) used in the South African pig classification system, to which the French system of on-line fat quality prediction might be applicable, was justified. It may be possible that, if the necessary modifications are made to accomodate the different measurements and formulas employed in South Africa, that the French system could be modified to predict fat quality in the South African classification system, to increase the detection of pigs with poor quality fat. The other method of carcass grading employed in South Africa is the measurement of BFT $(45 \mathrm{~mm})$ by means of the Intrascope. Not all abattoirs in South Africa use the HGP, as it is an expensive piece of equipment which is why the use of the BFT (45 $\mathrm{mm}$ ) measurement to predict fat quality could be very practical for smaller abattoirs utilizing the Intrascope. The HGP measures both the BFT ( $45 \mathrm{~mm}$ ) and LMC. Lean meat content and BFT (45 mm) were the carcass classification characteristics best correlated with IV. Iodine value, the internationally accepted measure of FA unsaturation, was well correlated with BFT $(45 \mathrm{~mm})$ with an r-value of -0.5610 , followed by LMC with an r-value of 0.5531 (Table 3). As was evident from Table 2, only the $\mathrm{P}$ group did not conform to the proposed limits for BFT $(45 \mathrm{~mm})$ measurements, ranging between the minimum value of $15 \mathrm{~mm}$, proposed by Davenel et al. (1999) and the maximum value of $20 \mathrm{~mm}$, proposed by Cannon et al. (1996) to achieve good quality BF. Pigs from the C, U and S groups conformed to the IV cut-off point of 70 proposed for good quality BF by Houben \& Krol (1983), Barton-Gade (1983, 1987) and Girard et al. (1988). No classification group could comply with the limit of $<57 \%$ LMC set by Davenel et al. (1999) for good quality BF. As LMC is one of the two criteria used to grade carcasses with the HGP, it is evident that recalculation of the French cut-off points is necessary if it is to be used to predict the fat quality of South African pigs.

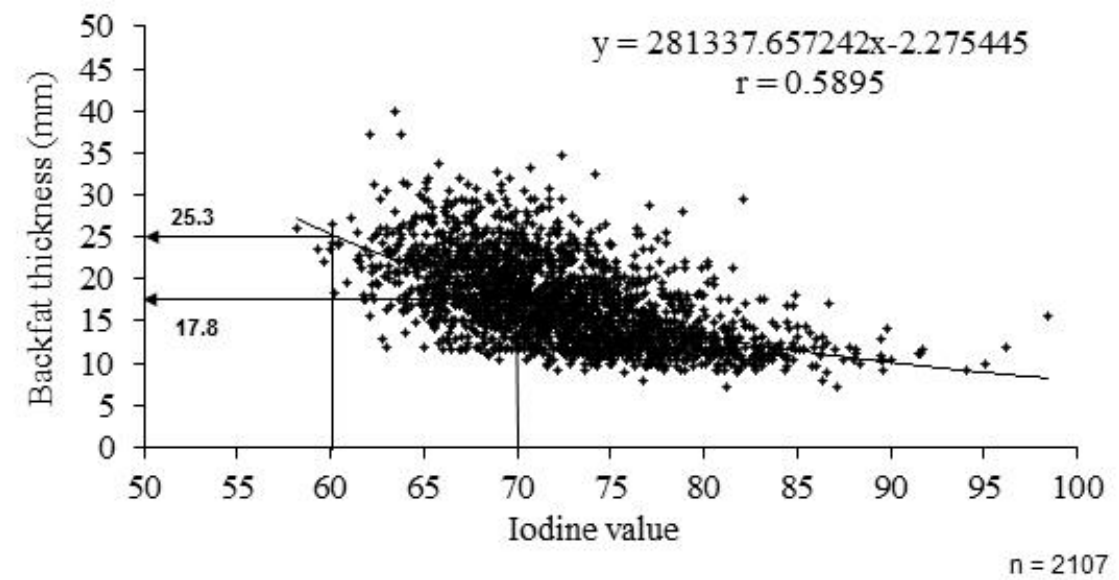

Figure 1 Scatterplot indicating the relationship between backfat thickness and iodine value.

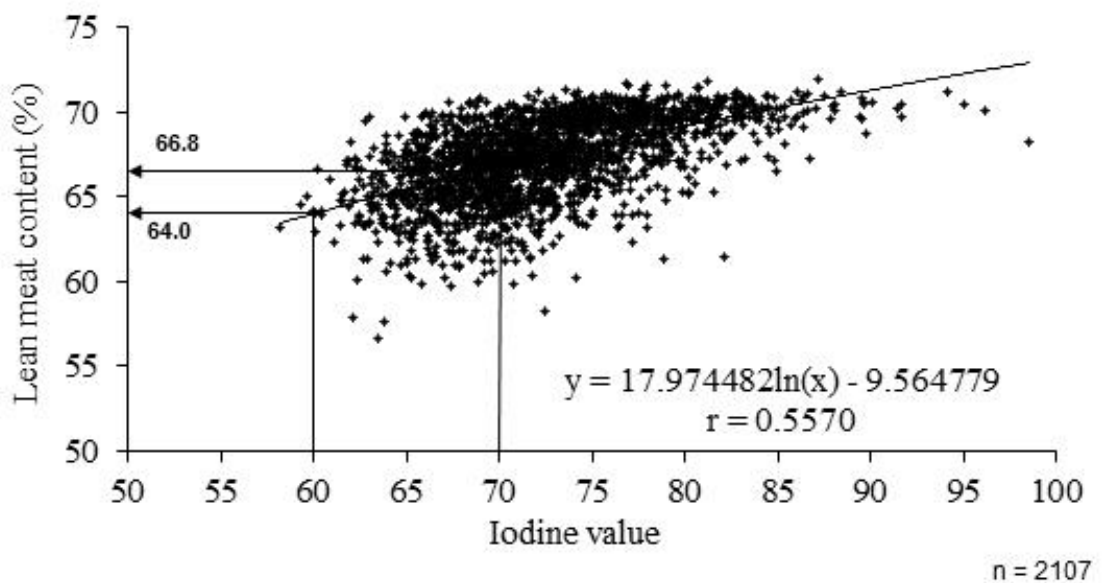

Figure 2 Scatterplot indicating the relationship between lean meat content and iodine value. 
Striving to find the alternative cut-off points for BFT $(45 \mathrm{~mm})$ and LMC for South African conditions, the relationships between IV, BFT ( $45 \mathrm{~mm}$ ) and LMC of all 2107 pigs were expressed on scatterplots (Figures 1 and 2). Trendlines were fitted to each scatterplot to determine the equation which best defined the particular relationship (with respect to the r-value). Table 4 indicates that the power equation best described the relationship between IV and BFT ( $45 \mathrm{~mm})$, while a logarithmic equation yielded the best fitted trendline on the scatterplot of IV against LMC. The y-values of the respective highlighted equations were substituted with the various international cut-off points in order to find out what the corresponding IV (the $x$-value) of South African pigs was. These values are tabulated in Table 5. It was found that a BFT (45 mm) of $>17.5 \mathrm{~mm}$, proposed by Cannon et al. (1996) corresponded to an IV of 70.6 in pigs, which is within close range to the IV of 70, proposed by various authors, to result in good quality BF. It was confirmed that the cut-off point for LMC of $<57 \%$, set by Davenel et al. (1999) was totally unrealistic, as it would result in pigs having a corresponding IV of 40.58 (Table 5).

Table 4 Equations for constructing best fit trendlines for predicting iodine values (y) from backfat thickness and lean meat content

\begin{tabular}{llll}
\hline Parameter & Fit option & Equation & $\mathbf{r}$ \\
\hline \multirow{3}{*}{ Backfat thickness } & Linear & $y=-0.5151 \mathrm{x}+54.5898$ & 0.5610 \\
& Power & $\mathrm{y}=\mathbf{2 8 1 3 3 7 . 6 5 7 2 \mathrm { x } ^ { - 2 . 2 7 5 4 }}$ & $\mathbf{0 . 5 8 9 5}$ \\
& Logarithmic & $\mathrm{y}=-38.0685 \mathrm{Ln}(\mathrm{x})+180.2106$ & 0.5645 \\
& Exponential & $\mathrm{y}=155.4251 \mathrm{e}^{-0.0309 \mathrm{x}}$ & 0.5878 \\
\hline \multirow{3}{*}{ Lean meat content } & Linear & $\mathrm{y}=0.2431 \mathrm{x}-49.7536$ & 0.5532 \\
& Power & $\mathrm{y}=21.3678 \mathrm{x}^{0.2681}$ & 0.5522 \\
& Logarithmic & $\mathrm{y}=17.9745 \operatorname{Ln}(\mathrm{x})-\mathbf{9 . 5 6 4 8}$ & $\mathbf{0 . 5 5 7 0}$ \\
& Exponential & $\mathrm{y}=51.7732 \mathrm{e}^{\mathbf{0 . 0 3 3 6 x}}$ & 0.5484 \\
\hline
\end{tabular}

Table 5 Calculation of corresponding iodine values (IV) for backfat thickness and lean meat content cut-off points proposed by literature

\begin{tabular}{llll}
\hline Parameter & $\begin{array}{l}\text { Cut-off } \\
\text { point }\end{array}$ & Reference & Corresponding IV \\
\hline & 15 & Davenel et al. (1999) & 75.50 \\
& 17.5 & Cannon et al. (1996) & 70.55 \\
Backfat thickness $(\mathrm{mm})$ & 18 & Prabucki (1991) & 69.68 \\
& 20 & Cannon et al. (1996) & 66.53 \\
\hline Lean meat content (\%) & 57 & Davenel et al. (1999) & 40.58 \\
\end{tabular}

By substituting the x-value with IV of 60 and 70, respectively, in each of the two above equations, alternative BFT $(45 \mathrm{~mm})$ and LMC measurements, which could be used to predict the fat quality of SA pork, was determined (Figures 1 and 2). Consequently, it can be deduced that an IV of $<60$ will be obtained at a BFT $(45 \mathrm{~mm}$ ) measurement of $>25.3 \mathrm{~mm}$ (Figure 1) and a LMC of $<64.0 \%$ (Figure 2). The meat industry measures BFT and LMC rounded off to one decimal, which is why these values were rounded off. The cut-off point for an IV of 60 was originally proposed by Fischer (1989b) as a requirement for fat utilized in firmcutting sausages like salami. Fat quality requirements are very strict for these products as soft fat can cause a lot of problems, such as fat exudation, smearing on cutting, insufficient drying and an oily appearance, which may lead to downgrading of the product, as discussed earlier. It is therefore not surprising that pigs from only the $U$ and $S$ groups could comply with these strict requirements. This implies that technically BF from only $U$ and $S$ pigs should be used for the manufacture of firm-cutting sausages like salami. 
In literature, however, the most common cut-off point for good quality BF, in terms of IV, is 70 , as proposed by various authors (Barton-Gade, 1983, 1987; Houben \& Krol, 1983; Girard et al. 1988). The added benefit of using the IV of 70 as a measure of good quality is that it is not directed towards a specific product, but is considered as a general requirement, covering the total spectrum of meat products. In addition, the French classification system utilizes the cut-off point of 70 as criterion for good quality fat, as stated by Davenel et al. (1999). If the IV of 70 is substituted as the $x$-value in the respective equations, a BFT (45 mm) measurement of $>17.8 \mathrm{~mm}$ (Figure 1), which is close to the limit of $<17.5 \mathrm{~mm}$ proposed by Cannon et al. (1996), and a LMC of $<66.8 \%$ (Figure 2) will result in BF of good technological quality in South African pigs. If the average of each group was taken into account, pigs from the $R, C, U$ and $S$ groups conformed to these new limits. It is proposed that, in South Africa, only pigs with a minimum BFT (45 mm) measurement of $17.8 \mathrm{~mm}$ and maximum LMC value of $66.8 \%$ will posses BF of good technological quality in terms of an IV of 70 unless we replace the maize in the pigs' diet with ingredients like barley which has a more saturated fatty acid profile.

Table 6 was constructed in an attempt to determine the probability of selecting pigs from the whole population of 2107 pigs and within the individual classification groups that conformed to the various international requirements proposed for IV of good quality fat. This table highlights the fact that a maximum IV of 60 is too strict for South African pigs to comply with, as less than $1 \%$ of the pigs in the $\mathrm{C}$ and $\mathrm{U}$ groups and only $0.14 \%$ of all pigs sampled during this study could conform to this requirement. If the limit for the maximum IV to result in good quality fat was raised to 65 and $66,<11 \%$ of all pigs sampled could comply with these limits, although a definite increase in the number of pigs in each group conforming to these IV was observed (Table 6). In the R group, $6.62 \%$ pigs had IV $<65$ and this amount almost doubled to $12.68 \%$ when an IV of 66 was taken to be the cut-off point for good quality BF. Table 6 also indicates that $35.9 \%$ of all 2107 pigs sampled had IV lower than 70, which is a more acceptable percentage. The percentage of pigs from the P group complying with a maximum IV of 70 was $7.79 \%$, in contrast with the $0.93 \%$ pigs from the same group conforming to a maximum IV of 66 . The $U$ group showed a pronounced increase from $25.5 \%$ pigs conforming to the maximum IV of $66 \%$ to $70.6 \%$ pigs that conformed to the IV requirement of $<70$. Similar increases were found in the other groups.

The probability of selecting pigs with good fat quality from the $\mathrm{C}$ group was $62.0 \%$, while there is a more than $70.0 \%$ chance that pigs in the $U$ group will have an IV $<70$ (Table 6). The possibility to select a pig carcass with good BF quality (IV <70) from the S group was $77.8 \%$. Consequently, it would be justified to propose that a maximum IV of 70 would be a more realistic cut-off point for South African pigs to conform to, to ensure that they possess BF of good technological quality.

Table 6 Probability of selecting pig carcasses within each classification group to conform to various iodine value (IV) requirements

\begin{tabular}{|c|c|c|c|c|c|c|c|}
\hline & \multicolumn{6}{|c|}{ Carcass classification } & \multirow{2}{*}{$\begin{array}{c}\text { All } \\
\text { pigs }\end{array}$} \\
\hline & $\mathbf{P}$ & 0 & $\mathbf{R}$ & C & $\mathbf{U}$ & $\mathbf{S}$ & \\
\hline Total number of carcasses & 539 & 539 & 544 & 347 & 102 & 36 & 2107 \\
\hline$\%$ Carcasses in classification group with IV $<60$ & - & - & - & 0.58 & 0.98 & - & 0.14 \\
\hline$\%$ Carcasses in classification group with IV $<65$ & 0.56 & 1.67 & 6.62 & 15.85 & 17.65 & 25.00 & 6.17 \\
\hline$\%$ Carcasses in classification group with IV $<66$ & 0.93 & 5.57 & 12.68 & 22.19 & 25.49 & 41.67 & 10.54 \\
\hline$\%$ Carcasses in classification group with IV $<70$ & 7.79 & 26.16 & 47.61 & 61.96 & 70.59 & 77.78 & 35.93 \\
\hline
\end{tabular}

The effect of applying the modified French system to South African pigs is illustrated in Table 7. If only BFT (45 mm) data are utilized, no pigs with a minimum BFT (45 mm) of $17.8 \mathrm{~mm}$ and maximum IV of 70 would be selected from the $\mathrm{P}$ group, while $25.0 \%$ of the pigs in the $\mathrm{O}$ group could comply with these requirements (Table 7). The probability of selecting pigs from the $\mathrm{R}$ group meeting these requirements is $53.0 \%$ (Table 7). As only BFT is measured by the Intrascope, abattoirs using this instrument for carcass grading can use this data to select pig carcasses with good fat quality. If LMC of $<66.8 \%$ and IV of $<70$ are the only criteria to be met, the $P$ and $O$ groups are totally excluded from having good quality BF (Table 7). The probability of selecting a pig with good fat quality from the R group, if these limits for LMC and IV are to be complied with, is $56.2 \%$, while $61.8 \%$ of the total number of pigs would probably meet these 
requirements. There was no difference in the percentage of pigs in the $\mathrm{C}, \mathrm{U}$ and $\mathrm{S}$ groups complying with these requirements when only BFT or only LMC data were utilized (Table 7).

Table 7 Probability of selecting carcasses with an iodine value $<70$ from the different classification groups after employing the modified French system of selecting good quality backfat

\begin{tabular}{|c|c|c|c|c|c|c|c|}
\hline & \multicolumn{6}{|c|}{ Carcass classification } & \multirow{2}{*}{$\begin{array}{c}\text { All } \\
\text { pigs }\end{array}$} \\
\hline & $\mathbf{P}$ & 0 & $\mathbf{R}$ & C & $\mathbf{u}$ & $\mathbf{s}$ & \\
\hline \multicolumn{8}{|l|}{ Utilizing only classification data } \\
\hline Total number of carcasses & 539 & 539 & 544 & 347 & 102 & 36 & 2107 \\
\hline \%Carcasses with IV <70 & 7.79 & 26.16 & 47.61 & 61.96 & 70.59 & 77.78 & 35.93 \\
\hline \multicolumn{8}{|l|}{ Utilizing only Backfat thickness data } \\
\hline Number of carcasses with BFT $(45 \mathrm{~mm})>17.8 \mathrm{~mm}$ & 0 & 4 & 400 & 347 & 102 & 36 & 889 \\
\hline$\%$ Carcasses with BFT $(45 \mathrm{~mm})>17.8 \mathrm{~mm}$ and IV $<70$ & 0 & 25.00 & 53.00 & 61.69 & 70.59 & 77.78 & 59.39 \\
\hline \multicolumn{8}{|l|}{ Utilizing only Lean meat content data } \\
\hline Number of carcasses with $L M C>66.8 \%$ & 0 & 0 & 276 & 347 & 102 & 36 & 761 \\
\hline \%Carcasses with LMC >66.8 and IV <70 & - & - & 56.16 & 61.96 & 70.59 & 77.78 & 61.76 \\
\hline \multicolumn{8}{|l|}{ Utilizing Backfat thickness and Lean meat content data } \\
\hline $\begin{array}{l}\text { Number of carcasses with BFT }(45 \mathrm{~mm})>17.8 \mathrm{~mm} \text { and } \\
L M C<66.8 \%\end{array}$ & 0 & 0 & 272 & 347 & 102 & 36 & 757 \\
\hline $\begin{array}{l}\text { \%Carcasses with BFT }(45 \mathrm{~mm})>17.8 \mathrm{~mm} \\
\text { and LMC }<66.8 \% \text { and IV }<70\end{array}$ & - & - & 56.25 & 61.69 & 70.59 & 77.78 & 61.82 \\
\hline
\end{tabular}

IV: iodine value; BFT (45 mm): backfat thickness measured $45 \mathrm{~mm}$ from the midline position; LMC: lean meat content.

Simultaneous employment of the modified French system (BFT $(45 \mathrm{~mm})>17.8 \mathrm{~mm}$ and LMC $<66.8 \%)$ as well as the maximum IV of 70 resulted in totally eliminating the $P$ and $O$ groups from having good fat quality (Table 7). As previously mentioned, the HGP utilizes both the BFT ( $45 \mathrm{~mm}$ ) and LMC measurements in the classification process. Employing the modified French system in South Africa, therefore increases the probability of selecting pig carcasses with good fat quality (IV <70) from the R group from $47.6 \%$ (if the Intrascope is employed) to $56.3 \%$ (if the HGP is employed). If the modified French system is employed, the probability of selecting pigs from all classification groups with good fat quality (IV <70) using the Intrascope measured fat quality (utilizing only BFT measurements) is $35.9 \%$. If the HGP is employed (utilizing BFT and LMC measurements) the probability of selecting pigs with good fat quality (IV <70) increases to $61.8 \%$. The overall picture is therefore also improved.

Higher prices per $\mathrm{kg}$ lean meat are paid for pigs in the $\mathrm{P}$ and $\mathrm{O}$ classification groups, making it more profitable to produce pigs in these classification groups. Increased BFT and decreased LMC can therefore be associated with increased fat quality. The reason for this is that thicker BF has a higher saturation level than thinner BF. In terms of IV the $\mathrm{P}$ to $\mathrm{R}$ groups had unacceptable IV, while the $\mathrm{C}$ to $\mathrm{S}$ groups had acceptable IV with good technological properties. The R group was found to be on the borderline in terms of fat quality. From the above findings, the assumption could be made that BFT and LMC can indeed be used to predict fat quality.

\section{Conclusions}

This study was the first survey ever to be performed on the relationship between carcass characteristics and BF quality of South African pigs. It provided an overview of the current BF quality status of South African pigs. The findings indicated that there were statistically significant differences in the BF quality of the different classification groups (PORCUS). In general, from a technological perspective, the $\mathrm{P}$ and $\mathrm{O}$ classification groups could not comply with the international standards proposed for good quality BF. From the study findings, the assumption could be made that BFT and LMC can be used to predict fat quality.

The carcass characteristics were well correlated with IV. In an attempt to determine the corresponding carcass characteristics for the IV, correlation analyses and scatterplots with best fit trendlines and equations were utilized. It was found that, if only the average IV of each group was taken into account, pigs from the R, $\mathrm{C}, \mathrm{U}$ and $\mathrm{S}$ groups had the highest probability of having good fat quality. From these calculations the French 
system of fat quality prediction was modified to conform to South African conditions. It was therefore proposed that South African pigs with a minimum BFT $(45 \mathrm{~mm})$ measurement of $17.8 \mathrm{~mm}$ and maximum LMC of $66.8 \%$, will have a high probability of possessing BF of good technological quality, in terms of an IV of $\leq 70$. By utilizing these limits, the $P$ and $O$ classification groups are totally eliminated from possessing the potential of producing BF of good technological quality. This is alarming, because most of the pigs produced in South Africa are graded as $\mathrm{P}$ and $\mathrm{O}$ carcasses.

An added benefit of this system is that these values are applicable to both methods of carcass evaluation (HGP or Intrascope) employed in South Africa. The probability of selecting pigs with good fat quality from the R group would, however, be higher if the HGP (employing both BFT and LMC measurements) were to be used. It must be stressed that employing these criteria does not guarantee BF of good quality, but it will decrease the risk of selecting a pig carcass with soft fat.

This research shows that classification for the fresh meat market is not suitable for the processing industry and that perhaps South Africa should have separate classification systems for the fresh meat and processing industries. Alternatively, there should be a price incentive for producers to produce pigs with lower IV as is the case in countries like Switzerland. As long as producers are penalized twice for fat production (once at the feed bill and then at classification) they will not produce fatter pigs in the $\mathrm{R}$ to $\mathrm{S}$ classification groups, with the potential of possessing good quality fat for the processing industry.

\section{Acknowledgements}

The authors would like to acknowledge the Red Meat Research and Development Trust of South Africa (RMRD-SA) for funding the research.

\section{References}

Affentranger, P., Gerwig, C., Seewer, G.J.F., Schwörer, D. \& Künzi, N., 1996. Growth and carcass characteristics as well as meat and fat quality of three types of pigs under different feeding regimens. Livest. Prod. Sci. 45, 187-196.

Andersen, J.R., Borggaard, C., Nishida, J. \& Rasmussen, A.J., 1999. Development of a NIR filter based instrument for on-line measurements of fat quality in pork. In: Proc. 45th Int. Congr.Meat Sci. Tech. Yokohama, Japan. pp. 372-373.

AOAC, 2000. Official Methods of Analysis (17th ed.). Association of Official Analytical Chemists, Inc., Arlington, Virginia, USA.

Bailey, C., Cutting, C.L., Enser, M.B. \& Rhodes, D.N., 1973. The influence of slaughter weight on the stability of pork sides in frozen storage. J. Sci. Food Agr. 24, 1299-1304.

Barton-Gade, P.A., 1983. Some experience on measuring the quality of pork fat. In: Fat quality in lean pigs. Ed: Wood, J.D., Meat Research Institute Special Report No. 2, EUR 8901 EN, CEC Workshop, Brussels, Belgium. pp. 47-52.

Barton-Gade, P.A., 1987. Meat and fat quality in boars, castrates and gilts. Livest. Prod. Sci. 16, 187-196.

Bothma, C., Hugo, A., Osthoff, G., Joubert, C.C., Swarts, J.C. \& de Kock, H.L., 2014. Effect of dietary conjugated linoleic acid supplementation on the technological quality of backfat of pigs. Meat Sci. 97, 277-286.

Bruwer, G.G., 1991. Implementering van nuwe klassifikasiestelsel. Porcus, June/July, 14.

Bruwer, G.G., 1992. The evaluation of pig carcasses for the development of a classification system. PhD. dissertation, University of Pretoria, South Africa.

Bruwer, G.G., Heinze, P.H., Zondagh, I.B. \& Naudé, R.T., 1991. The development of a new classification system for pig carcasses in the RSA. Porcus. Dec/Jan, 27-31.

Cannon, J.E., Morgan, J.B., McKeith, F.K., Smith, G.C., Sonka, S., Heavner, J. \& Meeker, D.L., 1996. Pork chain quality audit survey: Quantification of pork quality characteristics. J. Muscle Foods 7, 29-44.

Davenel, A., Riaublanc, A., Marchal, P. \& Gandemer, G., 1999. Quality of pig adipose tissue: relationship between solid fat content and lipid composition. Meat Sci. 51, 73-79.

Fischer, A., 1989a. Requirements asked from and properties found in pig's fatty tissue: On the processing of fats from slaughter animals. Part I. Die Fleischerei. 8, iv-v.

Fischer, A., 1989b. Requirements asked from and properties found in pig's fatty tissue: On the processing of fats from slaughter animals. Part II. Die Fleischerei. 9: iii-v.

Folch, J., Lees, M. \& Sloane-Stanley, G.H., 1957. A simple method for the isolation and purification of total lipids from animal tissue. J. Biol. Chem. 226, 497-509.

Gandemer, G., 2002. Lipids in meat quality and adipose tissues, changes during processing and sensory properties of meat products. Meat Sci. 62, 309-321.

Girard, J.P., Bout, J. \& Salort, D., 1988. Lipides et qualité des tissus adipeux et musculaires de porc, facteurs de variation. Journ. Rech. Porcine Fr. 20, 255-270. (Cited by Davenel et al., 1999). 
Hadorn, R., Eberhard, P., Guggisberg, D., Piccinali, P. \& Schlichtherle-Cerny, H., 2008. Effect of fat score on the quality of various meat products. Meat Sci. 80, 765-770.

Hart, P.C., 1956. Landbouwk. Tijdschr. 68, 813. (Cited by Houben \& Krol, 1983).

Häuser, A. \& Prabucki, A.L., 1990. Ergebnisse eines "screenings" betreffend die Fettqualität bei Mastschweinen in schweizerischen Schlachthöfen. J. Anim. Physiol. Anim. Nutr. 64, 36-42. (in German).

Houben, J.H. \& Krol, B., 1983. Pig fats and the manufacture and storage of meat products. In: Fat Quality in Lean Pigs. Ed: Wood, J.D., Meat Research Institute Special Report No. 2, EUR 8901 EN, CEC Workshop, Brussels, Belgium. pp. 15-26.

Hugo, A. \& Roodt, E., 2007. Significance of porcine fat quality in meat technology. Food Rev. Int. 23, 175-198.

Lea, C.H., Swoboda, P.A.T. \& Gatherum, D.P., 1970. A chemical study of soft fat in cross bred pigs. J. Agric. Sci., Camb. 74, 279-289.

Lo Fiego, D.P., Santoro, P., Macchioni, P. \& De Leonibus, E., 2005. Influence of genetic type, live weight at slaughter and carcass fatness on fatty acid composition of subcutaneous adipose tissue of raw ham in the heavy pig. Meat Sci. 69, 107-114.

Madsen, A., Jakobsen, K. \& Mortensen, H.P., 1992. Influence of dietary fat on carcass fat quality in pigs. A review. Acta Agric. Scand. 42, 220-225.

Marcoux, M., Pomar, C., Faucitano, L. \& Brodeur, C., 2007. The relationship between different pork carcass lean yield definitions and the market carcass value. Meat Sci. 75, 94-102.

Martin, A.H., Fredeen, H.T., Weiss, G.M. \& Carson, R.B., 1972. Distribution and composition of porcine carcass fat. J. Anim.Sci. 35, 534-541.

Miklos, R., Xu, X. \& Lametsch, R., 2011. Application of pork fat diacylglycerols in meat emulsions. Meat Sci. 87, 202-205.

Mortensen, H.P., Madsen, A. Bejerholm, C. \& Barton-Gade, P., 1983. Report No. 540. Nat.Inst. Anim.Sci. Copenhagen, Denmark. (Cited by Warnants et al., 1996).

NCSS, 2007. Statistical system for Windows. Number Cruncher Statistical Systems, Kaysville, Utah, USA.

Prabucki, A.L., 1991. Qualitätsanforderungen an Schweinefleisch. In: Schweinefleischqualität Qualitätsschweinefleisch. Tagunsbericht, 22 May 1991, ETH-Zürich, Institut für Nutztierwissenschaften. pp. 5-10. (in German).

Rampon, V., Gandemer, G., Le Jossec, P. \& Boulard, J., 1994. Qualité des tissus adipex chez le porc: situation en Bretagne. Journ. Rech. Porcine Fr. 26, 157-162. (Cited by Davenel et al., 1999).

SAMIC, 2014. Classification of Red Meat. A key to more effective marketing. Meat Classification Regulations No. R.863. Government Gazette of the Republic of South Africa. 1 September 2006. http://www.samic.co.za/download/Redmeat.pdf. Retrieved on 12 September 2014.

Ten Cate, C.L., 1968. "Fettausschwitzen" bei Rohwurst. Fleischw. 48, 877 (Cited by Fischer, 1989).

Verbeke, W., Van Oeckel, M.J., Warnants, N., Viaene, J. \& Boucqué, Ch.V., 1999. Consumer perception, facts and possibilities to improve acceptability of health and sensory characteristics of pork. Meat Sci. 53, 77-99.

Viljoen, J. \& Ras, M.N., 1991. The effect of different dietary fat sources, withdrawal times, and castration on the fatty acid composition of backfat in baconer pigs. S. Afr. J. Anim. Sci. 21, 76-79.

Villegas, F.J., Hedrick, H.B., Veum, T.L., McFate, K.L. \& Bailey, M.E., 1973. Effect of diet and breed on fatty acid composition of porcine adipose tissue. J. Anim. Sci. 36, 663-668.

Warnants, N., Van Oeckel, M.J. \& Boucqué, Ch.V., 1996. Incorporation of dietary polyunsaturated fatty acids in pork tissues and its implications for the quality of the end products. Meat Sci. 44, 125-144.

Wood, J.D., 1973. The fatty acid composition of backfat from Pietrain and Large White pigs. Anim. Prod. 17, 281-285. 